\title{
Information and Computer Technology (ICT) in Indian Banking System after Computerization
}

\author{
Shipra Gupta, Manisha Bhatia, Shipra Agarwal
}

\begin{abstract}
In Indian economy system, banking sector has an important role and after computerization, there is a great change came in it. In India, Now there are a lot of branches of banks. At present, banking sectors face a tough competition. Maximum growth rate are shown by those banks which have maximum profit. By the use of various technologies, banks cost may become minimum and profit may become maximum. In this manuscript, the effect has been studied on the banks after computerization. The effects are analyzed after use of information and computer technology in Indian banking systems after computerization. The selected banks for this study are SBI, PNB and UBI.
\end{abstract}

Keywords: Indian Banking system, digitalization, computerization of banks, Information and Computer Technology (ICT).

\section{INTRODUCTION}

The advancements in technology in recent past have greatly influenced almost every walk of life. As far as financial activities are concerned, the technological advancements has not only altered the manner in which customers connect with their finances and respective financial institutions but also transformed the way in which business/ financial organizations handle the various business activities and provide the services to the customers.

Digitalization means by the use of technology, conversion of data into a digital form. Execution of digitalization in financial institutions such as banks have vastly affected the work culture and influenced the customer services. Banking industry is the most important industry and reflects the health of economy of a country. Digitalization of banks diminishes human mistakes, helps in saving time and provides the scope for accommodation of new services to customers. From social to nation's point of view, banks need to reconsider the manner in which they work together to convey a superior customer experience and serve in the development of country.

The objective of the proposed study is to analyze the digitization, in context of our Mother Nation.

It is a well-known fact that technology has changed almost every walk of life. Technology influenced the banking industry too at a large and it has been adopted by the banking sector to stay abreast with the changing environment.

Revised Manuscript Received on April 25, 2019.

Shipra Gupta, Associate Professor, Department of Commerce, Graphic Era Hill University, Dehradun

Manisha Bhatia, Student of B.Com., Department of Commerce, Graphic Era Hill University, Dehradun

Shipra Agarwal, Department of Commerce, Graphic Era Deemed to be University, Dehradun changed scenario of the working of banks before and after

The banking sector has tremendously transformed itself in all means keeping the main aim of fulfilling customer requirements with least operational cost. In nutshell, because of changing times, banking industry witnessed changed demands of customers and adopted the technological developments with the aim to provide better services at reduced costs. The computerization of Indian banking sector was the first step towards digitization.

\subsection{Computerization of Banking Sector- A First Step towards Digitization}

Computerization of banking sector can be regarded as first step towards the adoption of technology in banking sector that influenced a lot not only the work culture of banks but also came as a sigh of relief for the customers of the banks and bank employees. Keeping this in view, the gain of computerization of banks, being a very fatal decision, is discussed first in report. The manual working culture in banking system had following associated shortcomings:

- $\quad$ Error prone

- Slow and time consuming operation

- $\quad$ Troublesome process of record keeping

- Problems in information retrieval

- Data Redundancy

- Inconsistent information

- Limited life time of paper

- $\quad$ Paper bound communication, bank circulars, office orders etc.

- Low customer satisfaction level

A digital computer operates with information, numerical or otherwise, represented in a digital form. The banking industry reflects the health of economy of a country. It enjoys the status of not only being one of the large industry but also very vital industry too. So in the last decade of twentieth century, RBI initiated the computerization of banks with the insight to

- diminish human errors,

- $\quad$ speed up the banking operations and help in saving time,

- facilitate information storage and retrieval,

- control redundancy of information,

- $\quad$ provide consistent information,

- $\quad$ avoid excess use of paper,

- $\quad$ provide safe storage of records for sufficiently longer period of time,

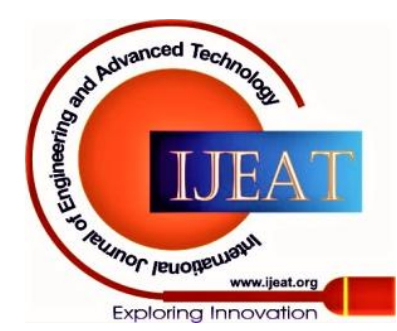


- provide timely information to staff and customers,

- $\quad$ improve customer services.

Computerization of Indian banks provided the benefits as expected, opened new avenues for further adoption of technology and paved a path towards Digitization (the conversion of data into a digital form with the adoption of technology is termed as Digitization) of banks. Further, revolutionary inventions in the field of Information and Computer Technology (ICT) and evolution of Internet drastically influenced the present day bank operations.

\section{PROBLEM STATEMENT}

Technology has greatly influenced our lifestyles and working cultures of almost all the organizations. The ICT and Internet has made this world as a global village. This motivated to undertake a study to observe the influence of technical revolutions in recent past on Indian banking sector. The problem statement is "The study aims at analyzing the impact of Digitization of Indian banks." For this the working of Indian banks before and after digitization is studied and analyzed.

\section{OBJECTIVES OF THE STUDY}

The main aim of this study is to analyze two different scenarios of Indian banking system i. e. before and after implementation of digitization. The specific objectives of the present research study are:

(i) To get acquainted with banking sector of India,

(ii) To understand the need of digitization of banks in India,

(iii) To analyze the impact of digitization of banks in India,

(iv) To access the impact of digitization of banks in current scenario,

(v) To ascertain the future scope by making use of technological advancements.

\section{RESEARCH METHODOLOGY}

\subsection{Research Design}

The research methodology in this study comprises of the following:

(i) Objective Formulation

(ii) Determining the data collection methods

(iii) Sample size selection

(iv) Data collection

(v) Data analysis

(vi) Findings.

(vii) Concluding the study

4.2 Sources of Data and Tools used for Data Collection

To perform a study one has to collect data from various sources. Both Primary and Secondary Data is used to carry out this study.

\subsubsection{Primary Data}

The Primary Data used in present study is the information collected

- $\quad$ from three banks e.g. State Bank of India, Punjab National Bank and Union Bank of India by visiting the branches in Dehradun, Uttarakhand, INDIA,
- from the relatives (parents, grandparents and sibling),

- from few known and unknown persons (bank customers) belonging to dissimilar socio-economic backgrounds.

Data Collection Tools:

- On site visit

- Interaction with relatives, bank customers and employees

\subsubsection{Secondary Data}

The Secondary Data used in present study is the information collected

- $\quad$ by accessing research articles on related topic, and

- by accessing web sites of State Bank of India, Punjab National Bank, Union Bank of India and Reserve Bank of India.

\section{Data Collection Tools:}

- $\quad$ Published articles in Newspaper, Magazines

- Official Websites of RBI, SBI, PNB and UBI

- $\quad$ Literature (pamphlet/ leaflet) provided by banks

\subsection{Sampling Technique, Population and Sample Size}

Sampling Technique Random-sampling technique is used for the selection of bank customers of SBI, PNB and UBI to gather information.

Population Known and unknown persons (bank customers) belonging to

dissimilar socio-economic backgrounds.

Sample size 25.

\section{LIMITATION OF THE STUDY}

To evaluate the customer's satisfaction level of service provided/ being provided by banks, the customers are selected by random sampling. Small Sample size is taken in this manuscript. While evaluating the customer service, data is collected from the opinions of depositors, borrowers, credit/debit card holders, only.

\section{FINDINGS, FUTURE SCOPE AND RECOMMENTATIONS}

\subsection{Findings}

In the current scenario, usage of Internet has revolutionized the entire banking system. People can 'bank anytime, anywhere' without having the need to visit the bank branch. This helps customers in saving time by completing work at the click of the button. NEFT (National Electronic Fund Transfer) and RTGS (Real Time Gross Settlement) has fascinated the consumers of banks largely. Now, fast and safe transfer of money from one account to another has become a reality and this has become possible only due to the emergence of digital banking. Further, cashless transactions have also controlled the corruption.

We are just witnessing the real power and role of digital banking by cashless transactions which has become possible today only because of digitization of banks.

The findings of the study are

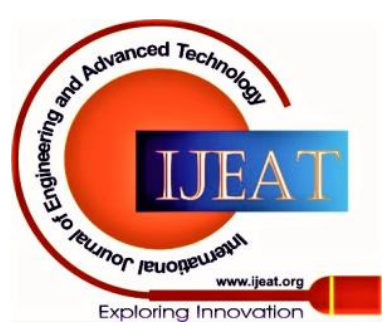


- First, the availability of technology and infrastructure is to be strengthening to support this relatively new model of banking so that a person sitting at a remote place is able to avail this facility.

- Second, there is still a need for more popularization of Indian digital banking through the use of television, social and print media so that more and more persons adopt this relatively a new way of banking.

- Third, digital banking has attracted the youth of modern generation and it will be the most preferred form of banking in the coming years.

- Fourth, a proper legal framework is to be strength to take care of the rights and obligation of the consumers.

- Fifth, to take adequate measures to tackle the security risk and operational risk aspects to avoid the frauds and hacking of accounts. The customers of banks should be familiarized with security aspects which can be done in the form of Do's and Don'ts.

\subsection{Some Recommendations for Secure Banking}

Digital banking allows online transactions hence online security issues should be taken seriously and addressed properly. To protect user's Account from attacks, the banks are supposed to alert its customers and are supposed to recommend the steps to be adopted regularly by the customers. Following are some preventive measures for secure digital banking:

(i) Make your password and account more secure

(ii) See devices that have used your account

(iii) Give attention to Security notifications

(iv) Prevent phishing with Password Alert

(v) Change unsafe passwords in your Account

(vi) Sign in on a device that's not yours

(vii) Lock or erase your lost phone or computer

\subsection{Future Scope}

The future developments in digital banking rely on the technological advancements in the field of Information and Computer Technology. Business Analytics has a good potential to bring a major change in banking sector. Enormous research is on in the field of computer technology particularly in Nano technology and Artificial Intelligence. The emergence of Nano technology shall change the whole computing scenario. At present, the research work in this field is not up to the level of implementation at a greater level. However, artificial intelligence is being used in several challenging domains and has shown quite encouraging outcomes.

AI can be a very prominent tool in the domain of banking sector. Artificial Intelligence is a field of computer science that attempts to simulate human intelligence and human capabilities with the help of machines, software, and computer platforms. It attempts to improve efficiency and achieve time-consuming tasks in minimal time. Implementation of AI has reduced human effort and decreases the chances of human error in several fields. Banks are moving towards AI because of several benefits mentioned below:

- $\quad$ AI enables error-free computation and lower chances of error when compared to humans.
It is extremely useful in reducing human efforts in laborious, repetitive, and tedious tasks.

It provides impressive predictive analysis for various banking situations.

It is easy to detect fraud and prevent any kind of disastrous activity.

Organizing and managing records and customer information, a huge volume of transactional data recording, becomes easy.

With applications like natural language processing and voice recognition, AI tools are interacting with humans and assisting them in solving problems efficiently and promptly.

Finally, there is no fear of exhaustion. AI can continue to use human intelligence capabilities without a break, rest, or sleep.

\section{CONCLUSION}

Following conclusions are drawn from the study:

(i) Now a day a wider range of e-banking services and products are used by banks for the convenience of the customers.

(ii) Now there are a lot of cashless transactions modes are available.

(iii) After the implementation of advanced technology in banking system, banks have faced many challenges for the safety and security of customer's funds and data. So, to remove this problem some special provisions should be made by banks

(iv) A well trained employees and expert technicians in computer field should be appointed by the banks for the security of the data and frauds.

(v) Special training, seminars and workshops should be conducted by the banking professionals from time to time.

\section{REFERENCES:}

1. Shipra Gupta, Comparative analysis of per share ratio of some selected Indian public sector banks, International Journal of Research in Commerce, Economics and Management, Vol. 2, No. 4, pp. 89-96, 2012.

2. Shipra Gupta, Analysis of leverage ratio in selected Indian public sector banks, Asian Journal of Management Research, Vol. 2 no. 4. 2012 .

3. Website of Reserve Bank of India, www.rbi.org.in

4. Report on trend and progress of banking in India, RBI, various years www.rbi.org.in.

5. Report on Trend and Progress of Banking of India, RBI, various years. www.rbi.org.in.

6. Website of State Bank of India, www.sbi.org.in.

7. Website of Punjab National Bank, www.pnb.org.in.

8. Website of Union Bank of India, www.ubi.org.in 